\title{
Barefoot Engineers: The Non-Mobility of Knowledge in a Knowledge-Transfer Project
}

\author{
By Stewart Allen (University of Edinburgh)
}

Knowledge transfer is an integral, yet oft neglected, component in the transfer of technology between different geographical and cultural milieus. This paper is based on fifteen months of participatory fieldwork within a CBO (community based organisation) in India that hosts up to thirty-five participants at any one time from the 'Least Developed Countries' index to train them in the maintenance and repair of solar photovoltaic technologies. The trainees, all of whom are women, and ideally grandmothers, are instructed for six months, without a common medium of language instruction, in circuit board assembly, soldering, testing, maintenance and repair, through a 'learning-by-doing' process. After six months, the women return home to solar electrify their communities. In the following paper, I argue that knowledge is created and sustained dynamically through an on-going alignment of objects and symbols, gestures and bodies, identities and environment. Knowledge and meaning are not so much embedded or inscribed in these materials but rather performed through them in a dynamic coalescence of networked doing. By employing a network metaphor to describe the interplay of bodies and gestures, and not only material semiotic alliances, I hope to re-situate the centrality of lived interactions between persons and material objects in the dynamic becomings of network assemblages.

\section{Introduction}

It is customary in academia to be presented with finely crafted papers setting forth well-honed arguments, clearly, and precisely. We often forget however, even as we write our own papers, the struggles and frustrations that go into, and contribute to, even the most well turned-out arguments. Ethnographic papers exist at the end of a long line of intermediaries many of which are rarely acknowledged, much less scrutinised. They are the culmination of what begins as a messy and localised research process, which itself is made possible by various geo-political and historical forces, travel and global-cultural flows. Participation and observation, material artefacts, identities and informants lead inextricably to field-notes and diagrams, photographs and videos. A continual bracketing, translation and transference of experience occurs from the writing of field-notes up to the first draft of a paper. The paper itself is subject to critiques, re-writes and suggestions as arguments and insights are expanded and tuned-up. Insights themselves - elusive kernels of originality and innovation that can make or break a researcher and contribute to the shape of an academic - are never sufficient on their own, but are themselves carried on the back of particular rhetorical conventions and tropes that provide shape, coherence, authority and stability. These stylistic arrangements ultimately transgress the boundary from page or screen to mind, via further intermediaries of membranes and retinas where they are again translated in the light of our own lived experience. The point I wish to stress is that the ethnographic text is the result of a continuing performance involving many different allies, all working together to perform the act of the text. These networks of intermediaries form chains of alliances which ultimately help mobilise the monograph 
and render it credible as a unit of force (Callon 1986: 14). Sensuous, intangible experience is made at once tangible, transportable and reproducible. The parallels between the processes of knowledge-transfer that I analyse below, and those that go into producing an ethnographic text such as this, are perhaps closer than we would like to imagine.

In this paper, through a critique of the widely utilised knowledge-transfer dichotomy of 'tacit' and 'explicit' knowledge models' (see Nonaka and Takeuchi 1995; Davenport and Prusak 1998; Osterloh and Frey 2000 etc.), I argue against the notion that knowledge is transferred as a reified entity between individuals or social locations and instead suggest that knowledge-transfer is better conceptualised as a performance that takes place across a range of heterogeneous actors. Drawing upon an actornetwork approach (see Callon 1986; Latour 1987, 1993; Law 1992 amongst others) to knowledge-transfer, I consider the patterns of relations that contributed to the failure of a knowledge-transfer project. I argue that knowledge does not so much move as an essential property between locations, but rather emerges as a result of a series of alliances involving a wide array of actors, both human and material. When a network metaphor of interacting elements is employed to describe knowledge-transfer, it compels us to recognise that knowledge is dynamically sustained across countless, untold intermediaries rather than passively transferred between a sender and receiver. All forms of knowledge as such, whether represented symbolically in texts or emerging skillfully through the body, are necessarily situated in practice (Lave and Wenger 1991).

\section{The Research Context}

My field-site was a community based development organisation, the Barefoot College, established in 1972 in a small village in central Rajasthan, India. It was initially founded to help develop self-reliance and sustainability in local communities through an integrated and practical approach to development. The principle idea was to combine the knowledge of urban professionals with rural skills and traditions in order to help local people identify and address the issues affecting them in a joint venture. This collaborative, needs-based approach to development led firstly to a twoyear ground-water survey of the surrounding area, constructing water hand-pumps where appropriate. Eventually, health and education programmes were established, and were later followed by rural industries and agriculture. In later years, the College adopted 'appropriate technologies', that is, technologies that are sustainable, energy efficient, use local materials wherever possible, and can be understood and controlled by local people without formal educational requirements (Carr 1985: 8).

With its emphasis on sustainability and appropriate technologies, the centre adopted solar photovoltaics as replacements for unsafe and inefficient kerosene lamps. Initially employed in the midwifery and healthcare section, photovoltaic lamps and lanterns were gradually put into practice throughout the organisation. Over time, the centre developed competence in the maintenance and repair of the systems themselves and

\footnotetext{
1 'Tacit' and 'explicit' knowledge has its origins in Ryle's (1945-6) distinction between 'knowing how' and 'knowing that'. Polanyi developed it further in Personal Knowledge (1958) and The Tacit Dimension (1967) summing it up with his now famous maxim that '... we know more than we can tell' (1967:4).
} 
with external funds began solar electrifying remote communities in India, providing skills-training to community members for the system's upkeep. This mirrored a general movement within the College of moving towards a 'barefoot' training model, inspired by the Chinese healthcare workers of the 1960s who were trained in basic healthcare to assist their own communities. Over time, the solar programme became the largest contributor to the organisation, providing much needed funds and exposure and eventually leading to the solar electrification of over 500 villages in ten states across India. The centre remains the first, and so far only 'campus' in India that is run solely on solar photovoltaic energy.

\section{The Programme}

In 2004, convinced by the effectiveness of the programme, the centre secured government funding as a development partner under the ITEC (International Technical Economic Cooperation) and SCAAP (Special Commonwealth African Assistance Programme) programme for the Indian Government's South-South development cooperation scheme. The ITEC programme, established in 1964, aims to provide relevant skills and capacity building in fields where India has developed expertise. Approximately five thousand participants from partner countries are involved every year. In the case of the centre, this has involved sending up to thirtyfive women to the training centre in India from the Least Developed Country list in Africa, as specified by the UN. Over the course of six months, the women are trained in the repair, maintenance and assembly of solar photovoltaic home systems. With ITEC funding, the women spend six days a week learning how to solder and assemble circuit boards, test and repair circuits, and install and maintain systems. When their six months are complete, the women return to their respective countries to install the systems in their communities and establish a Rural Electronic Workshop (REW) for their upkeep and the training of further community members.

In 2005, the first group of eighteen men and women from Ethiopia arrived at the campus to spend six months learning the skills necessary for the installation and maintenance of the solar systems. The Government of India provides funds for the air fares, accommodation, materials, food and training costs during the duration of their stay in India. Partners and donors provide funds for the photovoltaic solar home systems, including batteries, lamps, and lanterns plus six months of spare parts and equipment necessary for the REW. Since the first group of trainees completed the training, groups of women from the Least Developed Countries list have arrived every six months thereafter to be trained in the repair and maintenance of the systems.

Prior to travelling to India, the communities to be solar electrified are selected by the Director of the organisation in consultation with local NGOs of the host country. Villages are chosen based upon their low socio-economic status and remoteness from central grid electrification. Women, usually aged between forty and fifty, are often grandmothers who are either semi-literate or illiterate. They are favoured due to their roots in the community and unlikelihood of migrating upon their return to seek employment elsewhere - which was a problem previously experienced with men and young women. For the same reason - and it might be argued, somewhat rather punitively - no certificates are issued upon completion of the training to further hinder movement away from the receiving community. Two women from each village are 
chosen to provide support and comfort to each other during the training and upon their return.

\section{The Environment}

The first group of ITEC and SCAAP funded women arrived in September 2008. Thirty-four women from seven countries: Malawi, Tanzania, Ethiopia, the Gambia, Rwanda, Uganda, and Bhutan. Of these thirty-four women, five spoke good English; twenty-two were described as 'semi-literate', six as 'literate', and six as 'illiterate'. The centre defined 'semi-literacy' as having achieved less than five years of schooling. In practice, this worked out as having a basic grasp of reading, writing and numeracy. However, since all written materials provided by the centre are in English, even literate individuals not versed in the Latin alphabet were at a disadvantage.

The training block is situated in the 'old campus', a former tuberculosis sanatorium, previously rented from the government for the token sum of one rupee per month, but now privately owned by the centre. The old campus is a sprawling and neglected looking compound spread over twenty-eight acres, housing a school, crèche, craft section, solar cooker workshop, blacksmiths, various storage buildings, a computer training centre, mess area, and the solar workshop. The women live on campus in simple rooms adjacent to the workshop with two or three to a room.

The workshop is contained within one long rectangular building. Two work benches run down the central aisle. The benches are covered with the tools and equipment required to perform the work of a barefoot solar engineer: soldering irons, various wires of different colours and thickness, screw drivers, pliers, wire cutters and wire strippers, volt meters, circuit boards and drawers full of diodes, condensers, capacitors and resistors spill their contents over the floor and work surface. Large power supplies are placed periodically along the work benches as groups of women in brightly coloured saris huddle around LED displays testing circuit boards and lamps. Other groups of women sit in front of small printed circuit boards, concentration etched on their faces as they methodically thread various components through the openings. Near a wire mesh window, two women sit behind a large steel contraption, turning a handle as they carefully monitor the progress of a spindle of wire being slowly spun into a choke coil. Other women sit in a group on the floor on flattened cardboard boxes chatting away to each other while measuring out lengths of wire and tying them into bundles. The walls of the workshop are covered with large posters depicting resistance colour bands and their respective values in different languages. Various posters of basic greetings and phrases in French, Arabic, Swahili, English and Hindi Devangari cover the walls. A large map of the world adorns a further corner of the room; another has a poster from Ethiopia depicting the Marriot Hotel and other symbols of development from Addis Ababa. Overhead fans cut a slight breeze through the stifling heat but are kept to a minimum - to avoid cooling newly soldered components too quickly before they can be manipulated, as I learn later.

The 'master-trainers', that is, locally trained staff who have a minimum of four to five years experience are tasked with instructing the newly arrived trainees. They consist of both local men and women who have usually held various roles within the organisation before settling in the solar section. None of the master-trainers spoke fluent English, one or two had a basic grasp of written and spoken English. Over the 
course of the six months, the trainees picked up basic Hindi vocabulary necessary to express fundamental topics such as food, sickness, water, likes and dislikes.

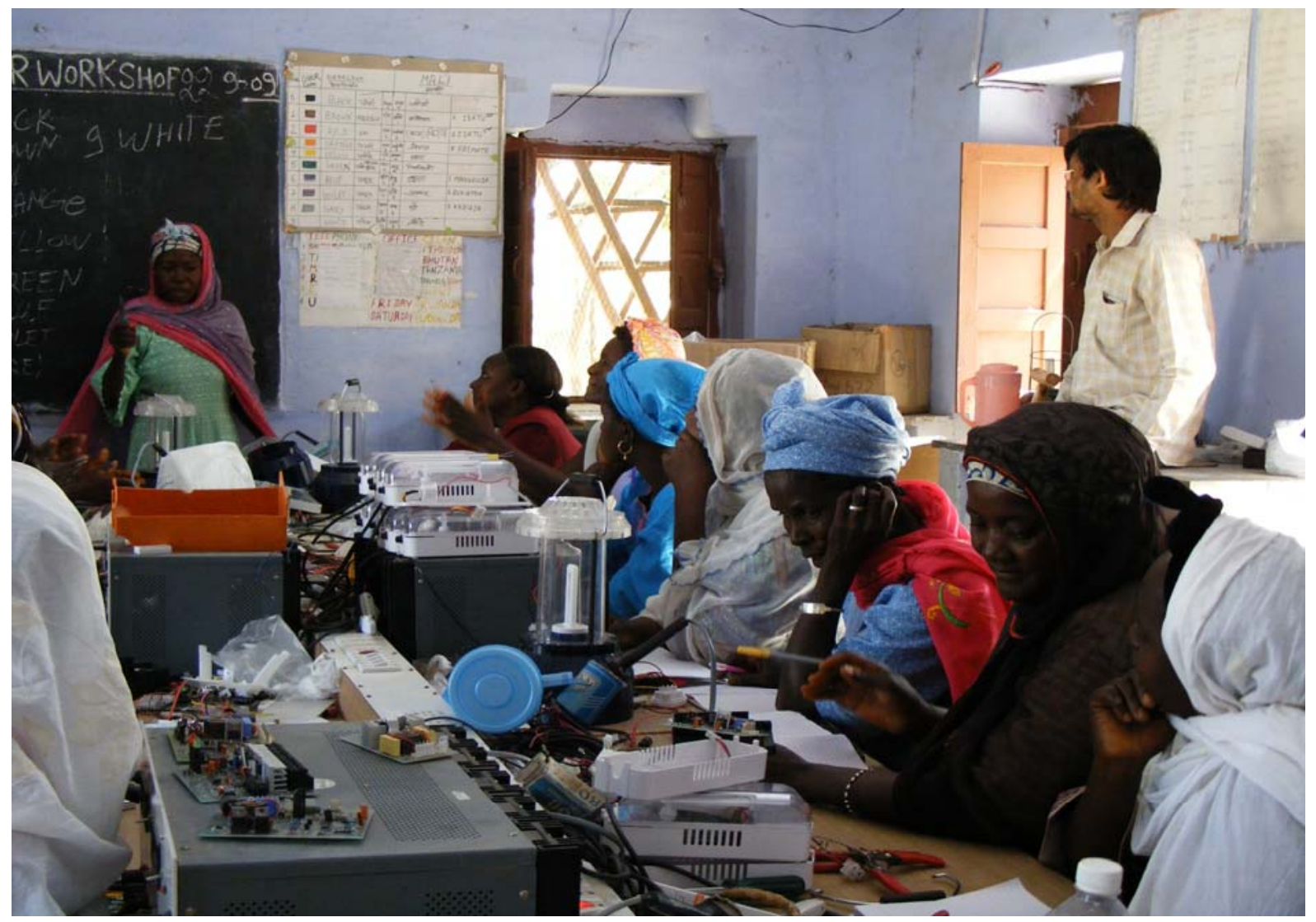

Training at the workshop

\section{From Training to Transfer}

The knowledge-transfer capabilities of the centre can be broadly de-limited within two dynamics. Firstly, the training component taking place in India. Here, knowledge is shared and hopefully transferred between individuals in a scripted learning environment. Learning takes place through a mixture of descriptive knowledge, that is, knowledge that can be expressed verbally or symbolically, and procedural knowledge, the knowledge and know-how required to perform a task. The second component of the knowledge-transfer occurs when the women return to their communities to implement the knowledge and skills they received in India.

The training, as Bruce (2007) notes, is similar to the training imparted by a technical college: trainees learn how to manufacture, assemble, operate and maintain circuits and systems but are not equipped to mathematically design, model or predict the behaviour of the circuits (Bruce 2007: 327). During the course of the six months, the trainees learn how to assemble and test three circuits: the fourteen component fixed lamp circuit, the seventy-one component solar lantern circuit, and the eighty-one component charge controller circuit, used to regulate the electric current drawn from or added to the battery. These primary skills are complemented with training in the fabrication of transformers and choke coils, an understanding of the electronic colour code and resistance values, how to install the system including placement of solar 
module, lamp fixings and battery, and how to use a multi-meter and a power supply to test circuits. Other skills, for example handling and use of tools such as wire strippers and wire cutters are learned in an informal manner over the course of the trainees' development.

The number of originating countries taking part in the programme presents a number of challenges during the training, the most significant of which is the lack of any kind of shared language. The first few weeks are therefore spent establishing a common terminology of English terms for equipment and numbers. Despite the fact that most, if not all, of the master-trainers have only a tenuous grasp of English themselves, English remains the preferred language for technical communication between participants. Thus, English terms for all tools, components, measurements and numbers are first established in a rote-repetition style of teaching and learning. The electronic colour code ${ }^{2}$, used to indicate the resistance value of resistors and other components, is the first group of words learned. Each number from 0-9 represents a particular colour on the electronic colour code which is marked in bands on the resistors themselves. For example, black $=0$, brown $=1$, red $=2$, orange $=3$ and so on.

The learning of resistance values and colours is followed by calculating resistance values and testing circuits. Each resistor used in a circuit is marked with four bands of colour representing its resistance rating. The first two colour bands represent resistance values, the third colour band the decimal multiplier and the fourth the tolerance value. So, a resistor with the colour coded marking of red, violet, black and red would give a resistance value of $27 \mathrm{ohms}$ or $27 \Omega$.

Further abstract reasoning is required for circuit testing. When a circuit has been completed, it is connected to a power supply for testing. By regulating the voltage or current administered to a circuit, it becomes possible to test whether the circuit is working to proscribed standards. The ability to correct the circuit fault relies, for the most part, in being able to communicate to the trainee either vocally or symbolically the what and the why rather than the how. Interviews with the solar trainees and master trainers bore out these oftentimes disparate knowledge practices.

Two women from the Gambia were confident about the training that they received at the workshop:

Yes, we understood everything. It was not a little bit easy at the beginning, because we had never been to school, we had never learned English, we couldn't speak it, we couldn't write. It was a bit difficult in the first month, but at the second month we start understanding the system and in the third month we are able to do it and we are doing it now by ourselves

(Interview transcript 14.01.09)

\footnotetext{
2 The electronic colour code is an international colour coded system used to indicate the values or ratings of electronic components. It was developed in the early 1920s by the Radio Manufacturers Association and commonly uses colour coded bands, particularly on resistors, to indicate resistance values.
} 
The master-trainers however expressed a different view during interviews. They maintained that the two trainees had picked up the practical hands-on component of the training but felt that they had understood little of the theoretical component. This proved to be a recurring theme. During further discussions with the master-trainers on the skills and knowledge that each trainee had acquired, it soon became clear that only the women with a strong grasp of English, both written and spoken, understood the theoretical aspects of the training. Some of these women were able to translate and explain the theory to non-English speaking members of their group. For the majority, however, the communication barrier was insurmountable. Theoretical aspects of the training, in particular fault finding and diagnostics, required explicit explanation in either spoken or written instruction. Procedural knowledge of the learning-by-doing type would not suffice in such instances.

The absence of a shared language in the workshop in India was the most obvious reason for the inability of the two Gambian women to diagnose, trouble-shoot and recognise resistance values. A further, yet less obvious problem that later came to light were the eyesight problems of the women; namely, they both suffered from undiagnosed eye problems. This impeded their ability to accomplish close-in work such as assembling circuits and identifying resistance markings on circuit components. At least one of the women also suffered from cataracts that severely impaired her ability to learn and perform the work adequately.

In this case, a malfunctioning actor contributed to the breakdown of the knowledge performance, hindering the ability of knowledge to be learned and performed. From an actor-network perspective, functioning eyes, shared language and literacy constitute mediating devices for the functioning of an actor-network. The suggestion of course is that explicit, abstract knowledge, contrary to the conventional view that such knowledge is static and disembodied, is rather, much like tacit knowledge, an emergent and wholly dynamic phenomenon contingent on a range of performative allies, both human and material. A body, much like a sociotechnical system, is also a network of interacting actors, comprising eyes and hands, but also gestures, identities and actions. When one actor fails, in this case the performed action of vision and the ability to read and understand certain symbols, then the entire performance itself is thrown into doubt. Explicit knowledge is situated in localising practices of production just as clearly as tacit knowledge is. Only in our desire to expunge the body from the production of explicit, and concomitantly, scientific knowledge, to erase any sign of its presence and its role in the production effort do we fail to acknowledge its situated character. As Shapin and Schaffer (1985) argue, the removal of the body from scientific discourse serves to render knowledge produced by science as pre-given, as universally valid and beyond doubt.

The history of science researcher, Otto Sibum (1999), researcher in the history of science, makes a similar argument with regard to scientific laboratory practice. Through the reconstruction of historical laboratory practices, he suggests that successful replication of an experiment requires craftsmanship and practical knowledge performed by experienced practitioners. This taken-for-granted craftwork, or tacit knowledge, he argues, remains essentially hidden from view in order to preserve the objectivity of the scientific knowledge generated. Such local knowledge practices, he argues, raises fundamental questions over science's claims to objectivity 
and challenges the universal validity claims of scientific knowledge (Otto Sibum 1999: 78). If skill, or gestural knowledge constitutes a mediating device between knowledge and its performance, then one could argue that vision and literacy are simply further, yet unacknowledged, mediating devices, or actors, in an actornetwork.

The replication of an experiment by way of rules and instructions can thus be similarly compared to the transfer of symbolically represented knowledge between people and locations. In this view, experiment and knowledge are not transferred or replicated but performed across a wide range of actors, both human and non-human. When knowledge is viewed as emerging in practice as opposed to being spatially transferred as a property, it challenges, as Sibum (1999: 83) observes, the fundamental distinction between epistemology and practice.

In the next section, I attempt to account for the failure of the performance of a knowledge-transfer project as I look to the relations and intermediaries between my field-site and the women tasked with transferring this knowledge between locations.

\section{Knowledge Transfer}

When their six months of solar training are complete, the women prepare to leave India and return to their respective countries. They will eventually install the solar photovoltaic systems in their communities and later establish a rural electronic workshop for their maintenance. I followed up by visiting one participating country, the Gambia, to observe the progress made there.

Approximately 300 kilometres long, and yet only thirty-five kilometres wide, the Gambia is Africa's smallest mainland country. With a population of approximately 1.7 million people, it is also one of its most densely populated. The Gambia occupies an area of roughly 10, 300 square kilometres and except for eighty kilometres of coastline, it is completely enclosed within Senegal. The Gambia is also one of Africa's poorest countries with a GDP estimated at \$1,400 per capita in 2009.

A local NGO works within each country covered by Barefoot College programmes to coordinate their projects on the ground. Representatives of these NGOs tend to get enrolled in the solar projects through attending presentations and seminars given by the Director at various international development conferences. Some of these NGOs meet the full cost of the solar equipment themselves; others act merely as coordinators, providing infrastructural support and consultancy services whereas the cost of the equipment is met by further partners and donors; this was the case in the Gambia. The Director then visits the country in question and in consultation with the local NGO, he will travel to selected villages to outline their proposals and seek agreement from the communities. The villages chosen for solar electrification are elected on the basis of their low socio-economic status and remoteness from central electricity grid lines. The women chosen to undergo training are further selected according to their age (preferably forty and over), their roots in the community, and their enthusiasm. I met with the project coordinator upon my arrival in the Gambia. He welcomed me warmly, but not without expectations. The project, as I was to discover over the following weeks, was failing on a number of levels. 
Four women from the Gambia have so far received training in India, two in 2006, and two in 2008/2009. I met and interviewed the most recent of these trainees while they were participating at the training centre in India. I met them again in their villages in the Gambia to find out how they were implementing the knowledge and skills they had gained in India. Over the course of several weeks, I interviewed the solar engineers themselves, inspected the solar systems and spoke to village elders and household users of the systems. What emerged was a story of malfunctioning bodies, worn-out artefacts, lost knowledge, and ultimately system breakdown.

Kankarang, the first village we visited, had fifty-seven solar lanterns installed in August 2007. Approximately one year later, all fifty-seven lanterns were found to be out of order, despite a battery life estimated at two to three years with correct maintenance. A further twelve households had deep-cycle battery problems that could not be rectified, despite a battery life estimated at eight to ten years. There was a similar story in the village of Kafenkeng, with all eighteen household lanterns no longer working. The women tasked with maintaining the systems were at a loss to explain the failure of the lamps and readily admitted that they could not diagnose the problem. They showed me around the rural electronic workshop, where large pieces of gleaming equipment used for making choke coils and transformers sat forlornly on work benches; the women had forgotten how to use them. They showed me the large deep-cycle batteries - used to power the workshop - sitting inertly in the corner, all life drained from them. One was being used as a door-stop. On the houses around the workshop, solar photovoltaic panels sparkled atop corrugated iron roofs, their purpose seeming more decorative now than practical. The women said they had also forgotten how to use the tools and equipment necessary to assemble the circuit boards, actions that only a few months previously they had performed daily.

While the inability of the women to diagnose and trouble-shoot problems was perhaps foreseeable, given that the knowledge required to perform such tasks was represented in descriptive form, their loss of know-how in relation to the operation of tools and components was less explicable. Namely, during the training in India, each group of women is given several sets of tools to use over six months. When learning the names of the tools, the women, the majority of whom have never encountered many of them before, pick them up, manipulate them, try them out and generally get a feel for them. Through a process of learning-by-doing, they quickly learn what each tool is capable of and the particular tasks that each one is suited to.

These skills and knowledges are learned and expressed by the women though their bodily hexis by way of corporeal sensations and feelings of muscular extension, contraction, force and pressure (Marchand 2010: 110). As Marchand (2008) notes in relation to apprenticeship style learning methods: 'Masonry and carpentry, like sport, dance and other skilled physical activities, are communicated, understood and negotiated between practitioners largely without words, and learning is achieved primarily through observation, mimesis and repeated exercise' (Marchand 2008: 247). The knowledge and ability to use different kinds of tools is therefore a sensorial, spatial and somatic knowledge set expressed through the performance of a sensorimotor system, coordinated movements, gestures and tools (ibid.: 257).

Once the women arrive back home, it takes from three to four months for the solar equipment to be packed, shipped and delivered to the villages. This time lag between 
training and actualisation contributes to a loss of both gestural knowledge and confidence to perform. Without regular performance of gestural actions in a scripted learning environment, both sensori-motor knowledge and confidence become impoverished. The gestural knowledge learned by the women over the course of their six-month training covers everything from knowing how to strip wires and solder, to more complicated tasks such as making choke coils and transformers and assembling circuit boards. The women performed these actions and gestures regularly, six days a week, for six months at the training centre in India. The knowledge required to carry out such tasks was expressed not only through muscles, memory and gestures but was also distributed ${ }^{3}$ (Hutchins 1995) throughout the immediate working environment providing an enabling framework of material interaction.

When the equipment does eventually arrive, the women are already adapting back into the routines of their previous life: farming, maintaining a household and looking after children. The lack of regular exposure to system maintenance means that much of their knowledge is gradually lost. Practical and skilful knowledge is a dynamic performance of both bodily gesture and identity building that cannot easily be stored or codified in symbolic form. Its robustness and transferability is dependent on regular enactments that help harden and sustain its network durability. The environment of the workshop in India, far away from their usual existence, further helped to foster the identity of the women as solar engineers. Indeed, despite the regular complaints about the monotonous spicy food, the lack of meat and fresh fruits, and missing their family, almost every woman I spoke to in India felt they were on a vacation from the everyday drudgery of running a household and working in the fields. Spending every day in a workshop, assembling circuits and lantern bodies, making choke coils and transformers with other women from other countries in Africa not only furnishes the trainee with a dynamic and embodied skill-set but also contributes to the identity construction of 'solar engineer'. Such an identity helps engender the confidence required to perform a role more usually allocated to men.

Strathern (1996) discusses the notion of 'network' and the desirability of perhaps 'cutting the network' and halting 'the flow', if those engaging with such orderings are to stop and speak about them. She notes that networks that are rendered contingent on interacting human elements for their durability have a fragile temporality that may depend on the immutability, and ironically, the homogeneity of identities for their durability (Strathern 1996: 523). Tacit knowledge is similarly in a state of constant flux when re-conceptualised as networks of interacting actors, rather than reified knowledge-sets. Knowledge becomes less a thing and more a process that is made durable and sustained through dynamic co-constructed interactions with other actors. It is less amenable to transfer, and hence less robust because of its fluctuating and mutable character.

\section{Conclusion}

It is commonly assumed that such embodied forms of knowledge as I have described are situated in character and arise through an interaction of human-actor and

\footnotetext{
${ }^{3}$ Distributed cognition is a theory developed by Edwin Hutchins that emphasises the social aspects of knowledge, in particular the interaction between individuals, material artefacts and environment. Despite a cognitive bias, his framework is a useful reminder of the interactive elements involved in knowledge performance.
} 
environment; explicit knowledge by contrast is of a determinedly non-situated character and can thus be abstracted and transported through the symbolic medium of texts with greater ease than embodied forms. However, this widespread dichotomy of knowledge as either abstract and located in the mind or as situated and rooted in practice, adheres to a backwards reading of knowledge in terms of its outcomes, rather than a forward reading in terms of the movements and improvisations that give rise to it (Ingold and Hallam 2007:3). When instead, we read knowledge as an emergent phenomenon performed between a range of heterogeneous actors, rather than an entity transferred between individuals across space, we are in a better position to consider the different actors that shape the outcome of knowledge-transfer projects. Knowledge in this sense is transformed and transmuted between different actornetworks (Latour 1999) rather than transferred as a distinct unit. The form of knowledge that emerges is contingent upon the actor-networks through which it is performed. Terms such as tacit and explicit then, refer not to different kinds of knowledge, but rather to different kinds of practice. Thus, while it may be said that an abstract task such as a multiplication problem can be performed in the mind, it is nevertheless routed in chains of practice (Lave 1988). Ingold argues: 'An intelligence that was completely detached from the conditions of life in this world could not think the thoughts it does' (2000: 25). Only by admitting non-human factors as mediating devices with the potential to shape and act upon a network are we able to account for how particular knowledge-transfer networks get formed, hold their shape, or in this case, fall apart.

\section{About the author}

Stewart Allen is a final year PhD student, in the department of anthropology, at the University of Edinburgh. He is currently on leave from his studies to take up an internship with Intel, Ireland, as an ethnographic researcher. He can be contacted at the following e-mail address: stewart.allen4@gmail.com

\section{Bibliography}

Bruce, A. (2007), 'Capability for the Manufacture of Photovoltaic System Components in Developing Countries'. Doctoral Dissertation. The University of New South Wales Sydney, Australia. Retrieved: 19/08/09. http://unsworks.unsw.edu.au/vital/access/manager/Repository/unsworks:2452

Callon, M. (1986), 'Some Elements of a Sociology of Translation: Domestication of the Scallops and the Fishermen of St Brieuc Bay', in J. Law \& P. Kegan (eds), Power, Action and Belief: A New Sociology of Knowledge, London: Routledge.

Carr, M. (1985), The AT Reader: Theory and Practice in Appropriate Technology, London: Intermediate Technology Publications.

Davenport T.H., and Prusak L. (1998), Working Knowledge: How Organizations Manage What They Know, Harvard Business School Press: Cambridge, MA.

Hutchins, E. (1995), Cognition in the Wild, Cambridge, MA: MIT Press. 
Ingold, T. (2000), The Perception of the Environment: Essays on Livelihood, Dwelling and Skill. London: Routledge.

Ingold, T and Hallan, E. (2007), 'Creativity and Cultural Improvisation: An Introduction', in Creativity and Cultural Improvisation, E. Hallam and T. Ingold (eds), Oxford: Berg.

Latour, B. (1987), Science in Action : How to Follow Scientists and Engineers Through Society, Milton Keynes: Open University Press.

Latour, B. (1993), We Have Never Been Modern. Cambridge, M.A.: Harvard University Press.

Latour, B. (1999), Pandora's Hope, Essays on the Reality of Science Studies, London: Harvard University Press.

John Law. (1992), 'Notes on the Theory of the Actor-Network: Ordering, Strategy and Heterogeneity', Systems Practice, 5: 379-93.

Lave, J. (1988), Cognition in Practice: Mind, Mathematics and Culture in Everyday Life, Cambridge: Cambridge University Press.

Lave, J. and Wenger, E. (1991), Situated Learning: Legitimate Peripheral Participation, Cambridge: Cambridge University Press.

Marchand, T.H.J. (2008), 'Muscles, Morals and Mind: craft apprenticeship and the formation of person', British Journal of Educational Studies, 56 (3): 245-271.

Marchand, T.H.J. (2010), 'Embodied Cognition and Communication: studies with British fine woodworkers', Journal of the Royal Anthropological Institute, 16 (1): 100-120.

Nonaka I, and Takeuchi H. (1995), The Knowledge-Creating Company: How Japanese Companies Create the Dynamics of Innovation, Oxford University Press: New York.

Osterloh, M., and Frey B.S. (2000), 'Motivation, Knowledge Transfer, and Organizational Firms', Organization Science, 11: 538-550.

Polanyi, M. (1958), Personal Knowledge: Towards a Post-Critical Philosophy, Chicago: University of Chicago Press.

Polanyi, M. (1967), The Tacit Dimension, Chicago: University of Chicago Press.

Ryle, G. (1945-46), 'Knowing How and Knowing That', Proceedings of the Aristotelian Society, 46:1-16.

Sibum, H. O. (1999), 'Experimental history of science', in Lindqvist, Svante (eds), Museums of Modern Science, Nobel Symposium, 112, Stockholm: Canton, Mass.: Science History. 
Shapin, S., and Schaffer, S. (1985), Leviathan and the Air-pump: Hobbes, Boyle, and the Experimental Life, Princeton: Princeton University Press.

Strathern, M. (1996), 'Cutting the Network', The Journal of the Royal Anthropological Institute, 2: 517-535. 